\title{
STAT3 signal transduction through interleukin-22 in oral squamous cell carcinoma
}

\author{
LUTFUN NAHER $^{1,2^{*}}$, TAMOTSU KIYOSHIMA ${ }^{1 *}$, IEYOSHI KOBAYASHI $^{1}$, HIROKO WADA $^{1}$, KENGO NAGATA ${ }^{1}$, \\ HIROAKI FUJIWARA $^{1}$, YUKIKO F. OOKUMA ${ }^{1,3}$, SATORU OZEKI $^{4}$, SEIJI NAKAMURA ${ }^{2}$ and HIDETAKA SAKAI ${ }^{1}$ \\ ${ }^{1}$ Laboratory of Oral Pathology and Medicine, Division of Maxillofacial Diagnostic and Surgical Sciences, \\ Faculty of Dental Science, Kyushu University; ${ }^{2}$ Department of Oral and Maxillofacial Oncology, \\ Division of Maxillofacial Diagnostic and Surgical Sciences, Faculty of Dental Science, Kyushu University; \\ ${ }^{3}$ Department of Pediatric Dentistry, Division of Oral Health, Growth and Development, Faculty of Dental Science, \\ Kyushu University, Fukuoka 812-8582; ${ }^{4}$ Section of Oral Surgery, Department of Oral and \\ Maxillofacial Surgery, Fukuoka Dental College, Fukuoka 814-0193, Japan
}

Received May 20, 2012; Accepted June 27, 2012

DOI: $10.3892 /$ ijo.2012.1594

\begin{abstract}
Interleukin (IL)-22 is a member of the IL-10 family. Its main targets are epithelial cells, not immune cells. We examined IL-22 signal transduction in oral squamous cell carcinoma (OSCC) cells. Immunohistochemical staining revealed that IL-22R was expressed more highly in OSCC compared to normal regions. An IL-22R signal was also observed in metastatic OSCC cells in the lymph node. RT-PCR showed that the human OSCC cell lines MISK81-5, HSC-3, HSC-4, SAS and SQUU-B expressed IL-22 receptor chains. Immunoblotting showed that IL-22 induced a transient tyrosine phosphorylation of STAT3 (pY705-STAT3) in MISK81-5 cells. The change in the serine phosphorylation of STAT3 was subtle during the examination periods. Simultaneously, pY705-STAT3 activation in HSC-3 cells was undetectable after IL-22 stimulation. Immunocytochemistry demonstrated that IL-22 induced the translocation of phosphorylated STAT3 into the nucleus of MISK81-5 cells. IL-22 temporarily upregulated the expression of anti-apoptotic and mitogenic genes such as Bcl-x, survivin and c-Myc, as well as SOCS3. IL-22 transiently activated ERK1/2 and induced a delayed phosphorylation of p38 MAP kinase, but negligibly involved the activation of NF- $\mathrm{B}$ in MISK81-5 cells. MISK81-5 and SQUU-B cells treated with IL-22 showed mild cellular proliferation. MISK81-5, HSC-4 and SAS cells treated with IL-22 downregulated the keratinocyte differentiation-related genes compared with unstimulated cells. Conversely, STAT3
\end{abstract}

Correspondence to: Professor Hidetaka Sakai, Laboratory of Oral Pathology and Medicine, Faculty of Dental Science, Kyushu University, 3-1-1 Maidashi, Higashi-ku, Fukuoka 812-8582, Japan E-mail: hsakaiop@dent.kyushu-u.ac.jp

*Contributed equally

Key words: IL-22, squamous cell carcinoma, STAT3, cell differentiation suppression by STAT3 siRNA strongly disrupted the downregulation of these genes by IL-22, but it did not significantly affect the activation of ERK1/2 by IL-22. The OSCC cells used in this study upregulated the expression of SERPINB3/4 (SCCA1/2), well-known SCC markers, following treatment with IL-22. These results indicate that IL-22 differentially activates the STAT3 signaling system depending on the type of OSCC. IL-22 may therefore play a role in tumor growth, cell differentiation and progression through STAT3-dependent and -independent pathways.

\section{Introduction}

More than $90 \%$ of all malignant epithelial tumors arising in the oral cavity are squamous cell carcinomas (SCC) $(1,2)$. Oral squamous cell carcinoma (OSCC) is one of the most common malignancies in humans. However, the overall survival rates have not substantially improved for decades (3) and a significantly increased incidence of OSCC in young subjects has been reported in recent decades $(4,5)$.

In general, varying degrees of inflammatory cell infiltration are observed around malignant tumors containing SCC. Cytokines or cytokine-related mediators have direct proliferative and anti-proliferative effects on tumor cells, and influence the cellular behavior of malignant cells (6-8). Interleukin (IL)-22 is a newly discovered member of the IL-10 family, and is expressed mainly in activated T, mast and NK cells $(9,10)$. Additionally, a subset of helper $\mathrm{T}$ cells abundantly produces IL-22, suggesting it plays a significant role in skin homeostasis and pathology (11). IL-22 receptor is a heterodimeric receptor of class II cytokine consisting of two chains, IL-22R1 and IL-10R2. IL-22R1 is expressed in non-immune tissues, including the skin, lungs, small intestine, liver, colon, kidneys, and pancreas (12), unlike IL-10R2, which is ubiquitously expressed in various organs and cells. Since IL-22 does not act between immune cells, but rather from immune cells to the non-immune cell compartment, IL-22 appears to be unique among cytokines. 
Although a few studies have so far addressed the roles of IL-22 in malignant cell proliferation and apoptosis, there are inconsistencies in the findings. IL-22 induces the activation of the major MAPK pathways in hepatoma cells (13), and increases the expression of many anti-apoptotic and mitogenic proteins following the activation of STAT3 (14). IL-22 can accelerate inducible nitric-oxide synthase expression in human colon adenocarcinoma cells (15). IL-22 protects human lung non-small cell carcinoma cells against chemotherapy via the activation of anti-apoptotic proteins (16). Conversely, IL-22 treatment induces the cell cycle arrest of murine breast adenocarcinoma EMT6 cells through the inhibition of ERK1/2 and AKT phosphorylation (17). The survival of mice with IL-22-expressing Colon 26 cells significantly increased in comparison to the control mice, suggesting that IL-22 might play a protective role in hosts with tumors (18). Although IL-22 appears to act variously in different carcinoma cells, there is little knowledge on the potential roles of IL-22 in OSCCs.

This study analyzed the signal transduction and genes induced in OSCC cells, to comprehensively evaluate the potential biological activity of IL-22 in OSCC. Additionally, the cell differentiation of OSCC cells by IL-22 was examined.

\section{Materials and methods}

Reagents. Recombinant human IL-6, IL-22 and TNF- $\alpha$ (Wako, Osaka, Japan), and mouse EGF (Sigma-Aldrich, St. Louis, MO, USA) were used for the study. Antibodies reactive to total STAT3, phospho-STAT3 (pY705, pS727), ERK1, phosphoERK1/2 (pT202/pY204), p38 $\alpha$ and phospho-p38 (pT180/ pY182) were purchased from BD Biosciences (Franklin Lakes, NJ, USA). The antibodies for total STAT3 (Santa Cruz Biotechnology, Inc., Santa Cruz, CA, USA) and IL-22R (Novus Biologicals, Littleton, CO, USA) were used for the immunocytochemical and immunohistochemical studies, respectively.

Samples and immunohistochemistry. Samples of primary OSCC and metastatic OSCC in the cervical lymph node diagnosed in the Department of Oral and Maxillofacial Surgery, Kyushu University Hospital in 2011 were immunostained in this study. This study was approved by the local research ethics committee.

Immunohistochemical staining was performed on $5 \mu \mathrm{m}$ paraffin sections. The endogenous peroxide activity was eliminated by treatment with $3 \%$ hydrogen peroxide in methanol for $20 \mathrm{~min}$. Non-specific protein binding was blocked with $10 \%$ goat serum for $20 \mathrm{~min}$, and then the sections were reacted with the primary antibody at $4^{\circ} \mathrm{C}$ overnight. The sections were incubated with the Fab' fragment of the secondary antibody conjugated with a peroxidase-labeled amino acid polymer (Histofine Simple Stain MAX PO, Nichirei, Japan) for $30 \mathrm{~min}$ at room temperature. After washing with PBS, the immunoreactivity was visualized with a solution of 3, 3'-diaminobenzidine and $<0.1 \%$ hydrogen peroxide (Nichirei). Subsequently, the sections were counterstained with hematoxylin. For the negative control, PBS was substituted for the primary antibody.

Cell lines and culture conditions. Human OSCC cell lines, MISK81-5 (19), HSC-3, HSC-4 (Japanese Cancer Research Resources Bank), SAS (20), and SQUU-B (21), a human keratinocyte cell line, $\mathrm{HaCaT}$, and a human erythroleukemia cell line, K562, were used. MISK81-5, HSC-3, HSC-4 cells and K562 cells were grown in $\alpha$-MEM (Invitrogen, Carlsbad, CA, USA) with $10 \%$ fetal bovine serum (Filtron, Brooklyn, Australia). SAS and SQUU-B cells were incubated in DMEM/F-12 (Invitrogen) with 10\% serum. HaCaT cells were maintained in DMEM (Invitrogen) with $10 \%$ serum.

Semiquantitative RT-PCR and real-time quantitative PCR analyses. The total RNAs were isolated using the SV Total RNA Isolation System (Promega, Madison, WI, USA), and cDNAs were generated from isolated total RNA with the SuperScript VILO cDNA Synthesis Kit (Invitrogen). Semiquantitative PCR was amplified with Advantage 2 (Clontech, Mountain View, CA, USA). Real-time quantitative PCR was performed using a Thermal Cycler Dice ${ }^{\circledR}$ Real Time System with SYBR ${ }^{\circledR}$ Premix Ex Taq ${ }^{\mathrm{TM}}$ II (Takara, Shiga, Japan).

A reference gene was determined among the various housekeeping genes (Table I). The relative expression level of each targeted gene was normalized using the $\Delta \Delta \mathrm{C}_{\mathrm{T}}$ comparative method, based on the reference gene threshold cycle (CT) values (22).

The mRNA expression of the STAT3 downstream genes, keratinocyte differentiation-related genes and SERPINB3/4 (Squamous Cell Carcinoma Antigen, SCCA1/2) genes, wellknown SCC markers, were examined in OSCC cells after IL-22 stimulation (Table I). The specificity of the PCR products was determined using a melting curve and/or gel electrophoresis.

Immunoblotting. Proteins were separated by $12 \%$ SDSpolyacrylamide gel electrophoresis, and transferred to an Immun-Blot ${ }^{\circledR}$ PVDF Membrane (Bio-Rad, Hercules, CA, USA). Antibodies bound to proteins were visualized by the ECL plus detection system (Amersham, Piscataway, NJ, USA). The protein concentration was estimated using a Micro BCA Protein Assay Kit (Pierce Biotechnology, Inc., IL, USA).

Immunocytochemistry for STAT3. Following incubation with the primary antibody, the cells were incubated in Alexa Fluor $^{\circledR} 568$ goat anti-rabbit IgG or 594 rabbit anti-mouse IgG (Invitrogen). The nuclei were counterstained with DAPI (Dojindo, Kumamoto, Japan).

Cell proliferation assay. The proliferation of IL-22-treated cells was quantified using the CellTiter-Glo ${ }^{\circledR}$ Luminescent Cell Viability Assay (Promega) and a Microplate Luminometer (Turner Biosystems, Sunnyvale, CA, USA). The cells were stimulated with $20 \mathrm{ng} / \mathrm{ml}$ of IL-22 every $24 \mathrm{~h}$ during the $48 \mathrm{~h}$ culture period.

Construction of an $\mathrm{NF}-\kappa \mathrm{B}$-responsive Luciferase Reporter Vector and the luciferase assay. Four tandem copies of the $\mathrm{NF}-\kappa \mathrm{B}$ consensus sequence were inserted upstream of the minimal promoter (minP) in pGL4.26 [luc $2 / \mathrm{minP} /$ Hygro] (Promega). After clonal selection of stably transfected MISK81-5 cells with hygromycin, MISK-pGL4-NF- $\kappa$ B cells were generated. Luminescence was measured using the One-Glo luciferase system (Promega) and the Microplate Luminometer.

Transient transfection of siRNA for STAT3. siRNAs for human STAT3 (GenBank Accession Number: NM_003150) 
Table I. Primer sets used in the present study.

\begin{tabular}{|c|c|c|}
\hline Target & & Sequence \\
\hline \multicolumn{3}{|c|}{ For semiquantitative RT-PCR } \\
\hline IL-22R1 & $\begin{array}{l}\text { sense } \\
\text { antisense }\end{array}$ & $\begin{array}{l}\text { 5'-CTC CAC AGC GGC ATA GCC T-3' } \\
\text { 5'-ACA TGC AGC TTC CAG CTG G-3' }\end{array}$ \\
\hline IL-10R2 & $\begin{array}{l}\text { sense } \\
\text { antisense }\end{array}$ & $\begin{array}{l}\text { 5'-GGC TGA ATT TGC AGA TGA GCA-3' } \\
\text { 5'-GAA GAC CGA GGC CAT GAG G-3' }\end{array}$ \\
\hline$\beta$-actin & $\begin{array}{l}\text { sense } \\
\text { antisense }\end{array}$ & $\begin{array}{l}\text { 5'-ATC TGG CAC CAC ACC TTC TAC AAT GAG CTG CG-3' } \\
\text { 5'-CGT CAT ACT CCT GCT TGC TGA TCC ACA TCT GC-3' }\end{array}$ \\
\hline \multicolumn{3}{|c|}{ For quantitative RT-PCR } \\
\hline Bcl-xL & $\begin{array}{l}\text { sense } \\
\text { antisense }\end{array}$ & $\begin{array}{l}\text { 5'-TAG GGT GGC CCT TGC AGT TC-3' } \\
\text { 5'-GTG AGG CAG CTG AGG CCA TAA-3' }\end{array}$ \\
\hline Survivin & $\begin{array}{l}\text { sense } \\
\text { antisense }\end{array}$ & $\begin{array}{l}\text { 5'-TTC TCA AGG ACC ACC GCA TC-3' } \\
\text { 5'-GCC AAG TCT GGC TCG TTC TC-3' }\end{array}$ \\
\hline c-Myc & $\begin{array}{l}\text { sense } \\
\text { antisense }\end{array}$ & $\begin{array}{l}\text { 5'-CGG ATT CTC TGC TCT CCT CGA C-3' } \\
\text { 5'-CCT CCA GCA GAA GGT GAT CCA-3' }\end{array}$ \\
\hline Cyclin D1 & $\begin{array}{l}\text { sense } \\
\text { antisense }\end{array}$ & $\begin{array}{l}\text { 5'-GTG CAT CTA CAC CGA CAA CTC CA-3' } \\
\text { 5'-TGA GCT TGT TCA CCA GGA GCA-3' }\end{array}$ \\
\hline SOCS3 & $\begin{array}{l}\text { sense } \\
\text { antisense }\end{array}$ & $\begin{array}{l}\text { 5'-CCC AAG GAC GGA GAC TTC GAT-3' } \\
\text { 5'-GAA ACT TGC TGT GGG TGA CCA T-3' }\end{array}$ \\
\hline TFRC & $\begin{array}{l}\text { sense } \\
\text { antisense }\end{array}$ & $\begin{array}{l}\text { 5'-GCG AGC ACT GAC CAG ATA AGA ATG-3' } \\
\text { 5'-TCC CGA TAA TGT GTT AGG ATT GTG A-3' }\end{array}$ \\
\hline$\beta$-actin & $\begin{array}{l}\text { sense } \\
\text { antisense }\end{array}$ & $\begin{array}{l}\text { 5'-TGG CAC CCA GCA CAA TGA A-3' } \\
\text { 5'-CTA AGT CAT AGT CCG CCT AGA AGC A-3' }\end{array}$ \\
\hline GAPDH & $\begin{array}{l}\text { sense } \\
\text { antisense }\end{array}$ & $\begin{array}{l}\text { 5'-GCA CCG TCA AGG CTG AGA AC-3' } \\
\text { 5'-TGG TGA AGA CGC CAG TGG A-3' }\end{array}$ \\
\hline $\mathrm{B} 2 \mathrm{M}$ & $\begin{array}{l}\text { sense } \\
\text { antisense }\end{array}$ & $\begin{array}{l}\text { 5'-CGG GCA TTC CTG AAG CTG A-3' } \\
\text { 5'-GGA TGG ATG AAA CCC AGA CAC ATA G-3' }\end{array}$ \\
\hline Loricrin & $\begin{array}{l}\text { sense } \\
\text { antisense }\end{array}$ & $\begin{array}{l}\text { 5'-TCA TGA TGC TAC CCG AGG TTT G-3' } \\
\text { 5'-TGC AAA TTT ATT GAC TGA GGC ACT G-3' }\end{array}$ \\
\hline Involucrin & $\begin{array}{l}\text { sense } \\
\text { antisense }\end{array}$ & $\begin{array}{l}\text { 5'-TAA CCA CCC GCA GTG TCC AG-3' } \\
\text { 5'-ACA GAT GAG ACG GGC CAC CTA-3' }\end{array}$ \\
\hline Keratin 1 & $\begin{array}{l}\text { sense } \\
\text { antisense }\end{array}$ & $\begin{array}{l}\text { 5'-AGA TCA CTG CTG GCA GAC ATG G-3' } \\
\text { 5'-TGA TGG ACT GCT GCA AGT TGG-3' }\end{array}$ \\
\hline Keratin 5 & $\begin{array}{l}\text { sense } \\
\text { antisense }\end{array}$ & $\begin{array}{l}\text { 5'-GAT AGC ATC ATC GCT GAG GTC AAG-3' } \\
\text { 5'-AGC CTC TGG ATC ATC CGG TTC-3' }\end{array}$ \\
\hline Keratin 10 & $\begin{array}{l}\text { sense } \\
\text { antisense }\end{array}$ & $\begin{array}{l}\text { 5'-AGG CTG GCA GCT GAT GAC TTC-3' } \\
\text { 5'-CAG GGT CAG CTC ATC CAG CA-3' }\end{array}$ \\
\hline Keratin 14 & $\begin{array}{l}\text { sense } \\
\text { antisense }\end{array}$ & $\begin{array}{l}\text { 5'-ACT TCA AGA CCA TTG AGG ACC TGA G-3' } \\
\text { 5'-CAG GGT CAG TTC GTC CAG CA-3' }\end{array}$ \\
\hline SERPINB3 & $\begin{array}{l}\text { sense } \\
\text { antisense }\end{array}$ & $\begin{array}{l}\text { 5'-GGC AGC AAT ACC ACA TTG GTT C-3' } \\
\text { 5'-TGT ATT GCC TCA TCA TCT GTA TGG A-3' }\end{array}$ \\
\hline SERPINB4 & $\begin{array}{l}\text { sense } \\
\text { antisense }\end{array}$ & $\begin{array}{l}\text { 5'-GGG ACT ATT GGC AAT GAT ACG ACA C-3' } \\
\text { 5'-AGG ACC TTG GCC TGT ACA TCC TC-3' }\end{array}$ \\
\hline
\end{tabular}

and GAPDH, and a siRNA universal negative control (SigmaAldrich) were used as a target and positive and negative controls, respectively. The cells were transfected with siRNA (10 nM) using the Lipofectamine RNAiMAX (Invitrogen).

Statistical analysis. All experiments were independently repeated at least three times. Statistical analysis was performed using the one-way ANOVA with the Tukey-Kramer comparison test, Dunnett's test or Student's t-test. A p-value $<0.05$ or $<0.01$ was considered to indicate statistically significant differences.

\section{Results}

Human oral squamous cell carcinoma cell lines express $I L-22$ receptor chains. First, we immunohistochemically examined 
A

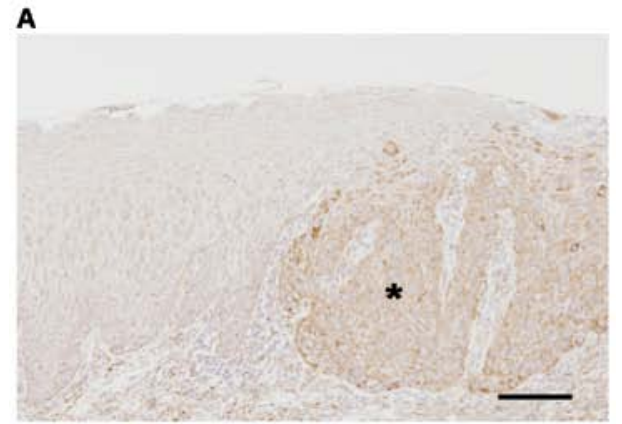

B

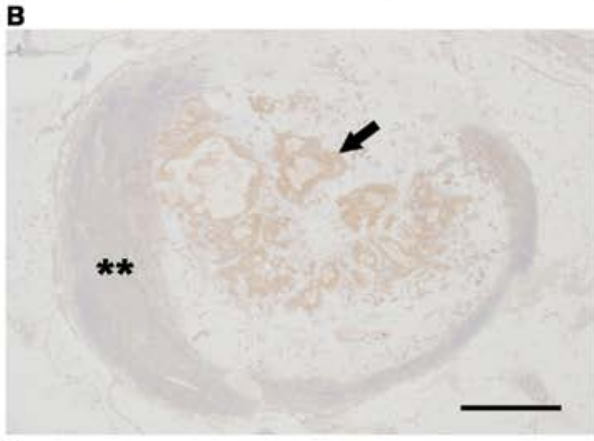

C

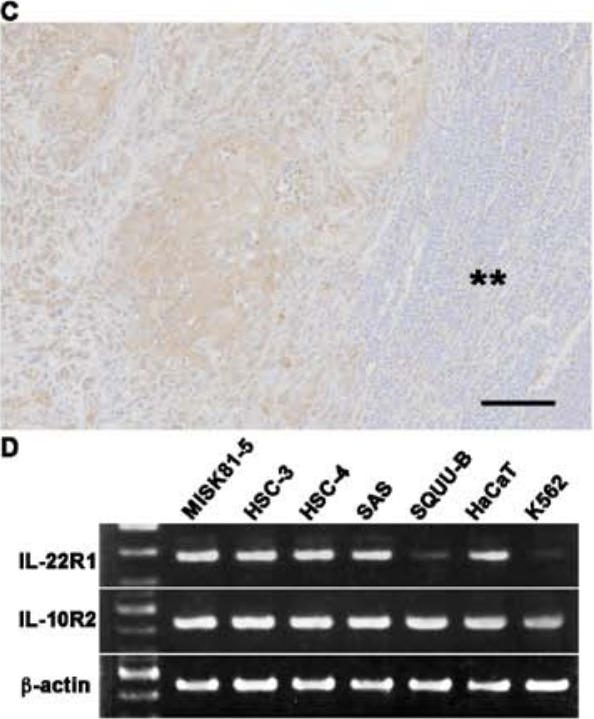

Figure 1. IL-22R is expressed in the OSCC of the extirpated samples and OSCC cell lines. (A) IL-22R immunostaining was observed in four of the seven extirpated samples, including some normal regions. The immunoreactive intensity for IL-22 was increased in the OSCC region (right side; *) compared with that in the normal oral epithelium (left side). Scale bar, $100 \mu \mathrm{m}$. (B) Metastatic carcinoma cells in the cervical lymph node (**) showed strongly positive signals for IL-22R (arrow). Scale bar, $1 \mathrm{~mm}$. (C) IL-22R positive signals in metastatic carcinoma cells in the cervical lymph node (**) in another case. Scale bar, $100 \mu \mathrm{m}$. (D) IL-10R2 and IL-22R1 mRNA expressions were examined by semiquantitative RT-PCR. $\beta$-actin was used as an internal control.

the IL-22R expression in OSCC. The immunostaining revealed that the intensity increased in the OSCC cells, although weak IL-22R signals were also observed throughout the normal oral mucosa (Fig. 1A). Significant staining was also observed in the metastatic carcinoma cells present in the cervical lymph node (Fig. 1B and C).

IL-22R1 and IL-10R2 were both detectable in all tested OSCC cells (Fig. 1D), although their expression intensity varied. HaCaT cells served as a positive control (23). K562 cells were analyzed as a negative control for IL-22R1. The
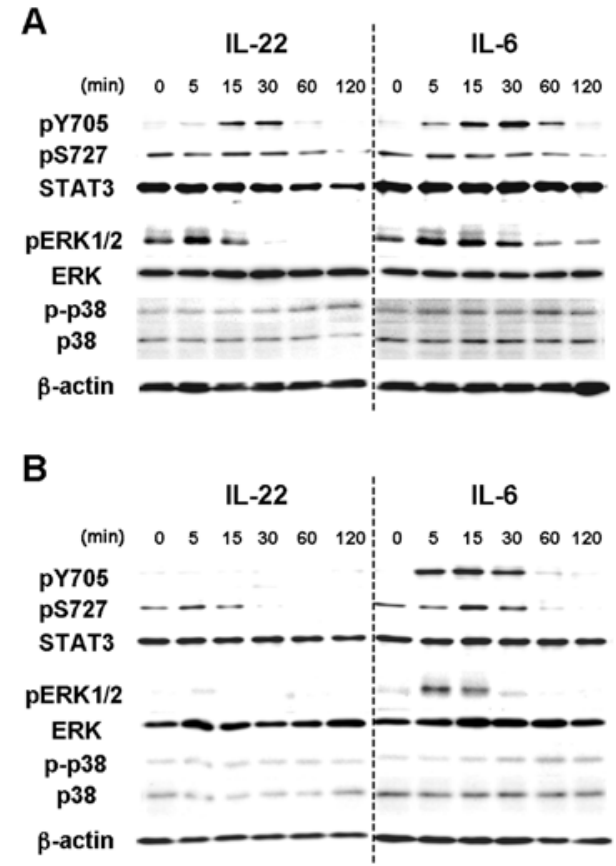

Figure 2. IL-22 induces transient STAT3 phosphorylation and the phosphorylation of several members of the MAPK pathways in MISK81-5, oral squamous cell carcinoma cells. (A) MISK81-5 and (B) HSC-3 cells were incubated with IL-22 $(20 \mathrm{ng} / \mathrm{ml})$ or IL-6 $(20 \mathrm{ng} / \mathrm{ml})$ for varying times up to 120 min. (A) IL-22 and IL-6 induced pY705-STAT3 in MISK81-5 cells within 15 and $5 \mathrm{~min}$, respectively. IL-22 induced transient tyrosine phosphorylation of STAT3 in MISK81-5 cells with similar kinetics to IL-6. IL-22 and IL-6 induced subtle changes in pS727-STAT3 within the tested time periods. IL-22 induced a transient activation of ERK1/2 in MISK81-5 cells and also induced a delayed phosphorylation of p38 MAP kinase, similar to IL-6. (B) In HSC-3 cells, pY705-STAT3 was undetectable after IL-22 stimulation, although transient pY705-STAT3 expression was induced after IL-6 stimulation. IL-22 and IL-6 induced the transient serine phosphorylation of STAT3. HSC-3 cells stimulated with IL- 6 showed activation of ERK1/2 and p38 MAP kinases similar to that in MISK81-5 cells. However, the activation in HSC-3 cells was undetectable after IL-22 treatment. All findings represent the results of three independent experiments.

mRNA expression of IL-22R1 and IL-10R2 were also detectable in all the OSCC cell lines under serum-free conditions (data not shown).

MISK81-5 squamous cell carcinoma cells are responsive to $I L-22$. IL-22 induced the tyrosine phosphorylation of STAT3 (pY705-STAT3) in MISK81-5 cells within 15 min, peaking at $30 \mathrm{~min}$ (Fig. 1B), as seen in othercell lines by IL-22 (13,17,24-26). This phosphorylation was transient, and decreased toward the baseline until reaching barely detectable levels after $120 \mathrm{~min}$. The change in the serine phosphorylation of STAT3 (pS727STAT3) in MISK81-5 cells treated with IL-22 was subtle within the tested periods. At the same time, pY705-STAT3 increased within 5 min and still remained detectable in MISK81-5 cells at least $1 \mathrm{~h}$ after IL-6 stimulation. IL-6 treatment led to a subtle change in pS727-STAT3 within the tested periods. Conversely, IL-6 had a similar effect on pY705-STAT3 in HSC-3 cells, but the activation of pY705-STAT3 by IL-22 was not detectable during the tested periods (Fig. 2A).

IL-22 induced the phosphorylation of ERK1/2 in MISK81-5 cells within $5 \mathrm{~min}$, but the level slightly decreased at $15 \mathrm{~min}$ (Fig. 2B). This phosphorylation decreased to below control 
levels after $30 \mathrm{~min}$. IL-22 also induced a delayed phosphorylation of p38 MAP kinase after $60 \mathrm{~min}$. Although the peak of pERK1/2 was noted at $15 \mathrm{~min}$, similar results were obtained in MISK81-5 cells treated with IL-6. The activation of ERK1/2 and p38 MAP kinases was undetectable in HSC-3 cells after IL-22 treatment (Fig. 2A). IL-6 showed similar activation of ERK1/2 and p38 MAP kinases to that in MISK81-5 cells treated with IL-22 or IL-6.

IL-22 induces the translocation of pSTAT3 into the nucleus of MISK81-5 cells. STAT3 expression was noted in both the nucleus and cytoplasm of MISK81-5 cells before IL-6 stimulation, and was observed in the nucleus of many MISK81-5 cells within 5 min after IL-6 stimulation. STAT3 was again detectable in the cytoplasm after $30 \mathrm{~min}$ (Fig. 3A). The increased signal for pSTAT3 in the nucleus of MISK81-5 cells was observed at 30 min after IL-22 treatment (Fig. 3B), whereas no nuclear translocation of pSTAT3 was detected in HSC-3 cells treated with IL-22 (Fig. 3C).

IL-22 promotes the expression of anti-apoptotic and mitogenic genes in MISK81-5 cells. Since cytokine stimulation can induce instability in the housekeeping gene expression (27-29), $\mathrm{B} 2 \mathrm{M}$ was selected as the internal control among the various housekeeping genes tested using the geNorm system (http:// medgen.ugent.be/ jvdesomp/genorm).

The expression of anti-apoptotic proteins, Bcl-xL and survivin, and the mitogenic proteins, c-Myc and cyclin D1, and the suppressor for STAT3, the SOCS3 gene, were examined in MISK81-5 cells treated with IL-22 (Fig. 4). The expression of Bcl-xL and c-Myc genes exhibited a 2.4-fold increase, and peaked at 30 and $60 \mathrm{~min}$ after IL-22 stimulation, respectively (Fig. 4A and C). However, the c-Myc gene expression dramatically decreased to $40 \%$ of the basal level at $120 \mathrm{~min}$. SOCS3 expression was markedly induced at $30 \mathrm{~min}$ after IL-22 stimulation, it exhibited a 37-fold increase at $60 \mathrm{~min}$ and subsequently decreased at 120 min (Fig. 4E). IL-22 significantly increased the gene expression of survivin at 60 and $120 \mathrm{~min}$. The expression of cyclin D1 significantly decreased at 30 and 120 min (Fig. 4B and D).

SOCS3 expression was markedly induced at $30 \mathrm{~min}$ in the HSC-4 cells after IL-22 stimulation, it peaked at $60 \mathrm{~min}$, and subsequently decreased at $120 \mathrm{~min}$ (Fig. 4G). Similar results were observed for IL-22 stimulation in the SQUU-B cells. However, its expression dramatically decreased to less than the baseline level at $120 \mathrm{~min}$ (Fig. 4I). The SOCS3 expression in the SAS cells treated with IL-22 was gradually increased from $30 \mathrm{~min}$ to $120 \mathrm{~min}$ (Fig. $4 \mathrm{H}$ ).

IL-22 slightly induces tumor cell proliferation in vitro and the cellular NF- $\kappa$ B activation status. The effect of IL-22 on the proliferation of MISK81-5, HSC-4, SAS and SQUU-B cells in vitro was examined. MISK81-5 and SQUU-B cells treated with IL-22 showed 1.3- and 1.1-fold increase in viability compared with control samples, respectively. A significant difference was demonstrated between the IL-22-treated cells and controls $(\mathrm{p}<0.01)$. Although HSC-4 and SAS cells were subtly increased by IL-22, there was no significant difference in the viability of these cells between the IL-22-treated cells and controls (Fig. 5A).
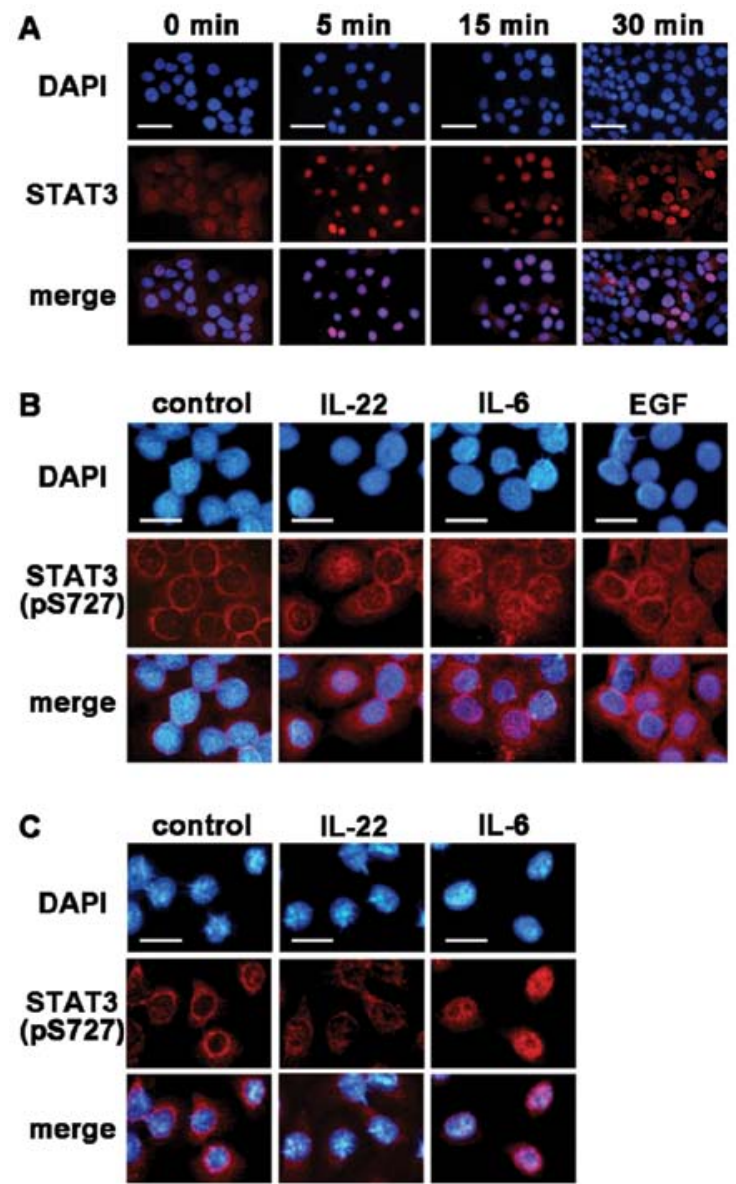

Figure 3. IL-22 translocates pSTAT3 into the nucleus in MISK81-5 cells. (A) MISK81-5 cells were either untreated as a control (left) or treated with IL-6. IL-6 led to the rapid translocation of most of the STAT3 into the nucleus of MISK81-5 cells within $5 \mathrm{~min}$. After $30 \mathrm{~min}$, STAT3 was noted in the cytoplasm again. (B) MISK81-5 or (C) HSC-3 cells were either untreated as a control (left) or treated with IL-22 or IL-6 for 30 min. (B) The translocation of pSTAT3 into the nucleus was noted in MISK81-5 cells treated with IL-22 as well as with IL-6 or EGF. (C) In HSC-3 cells, the translocation of pSTAT3 into the nucleus was not observed after IL-22 stimulation, but translocation was induced by IL-6. Alexa Fluor ${ }^{\circledR}$ IgG was used as the secondary antibody (red); nuclei were counter-stained with DAPI (blue); EGF was used as control for stimulating the activation of STAT3. (A) Scale bar, $30 \mu \mathrm{m}$; (B and C) scale bar, $10 \mu \mathrm{m}$.

MISK-pGL4-NF- $\kappa$ B cells stimulated with 50 and $100 \mathrm{ng} / \mathrm{ml}$ TNF- $\alpha$ demonstrated significant 3.6-fold and 3.8-fold increases in luciferase activity, respectively, compared with the unstimulated cells (Fig. 5B). However, the effects of IL-22 and IL-6 were subtle or negligible. No significant difference was noted between the stimulated and control samples (Fig. 5B).

IL-22 reduces the expression of keratinocyte differentiationrelated genes. The expression of the involucrin (IVL) and keratin 1 (KRT1) genes significantly decreased to $20 \%$ and $\sim 5 \%$ of control levels by IL-22 treatment, respectively ( $<<0.01$; Fig. 6A). In addition, the expression of these genes in HSC-4 cells significantly decreased to $\sim 50 \%$ after IL-22 treatment (p<0.01) (Fig. 6B). The KRT1 expression in SAS cells significantly decreased to $\sim 10 \%$ after IL-22 treatment $(\mathrm{p}<0.01)$ (Fig. 6C). The expression of keratin 10 (KRT10) was unchanged in the MISK81-5 (Fig. 6A), HSC-4 (Fig. 6B), SAS (Fig. 6C) and SQUU-B cells treated with IL-22. 

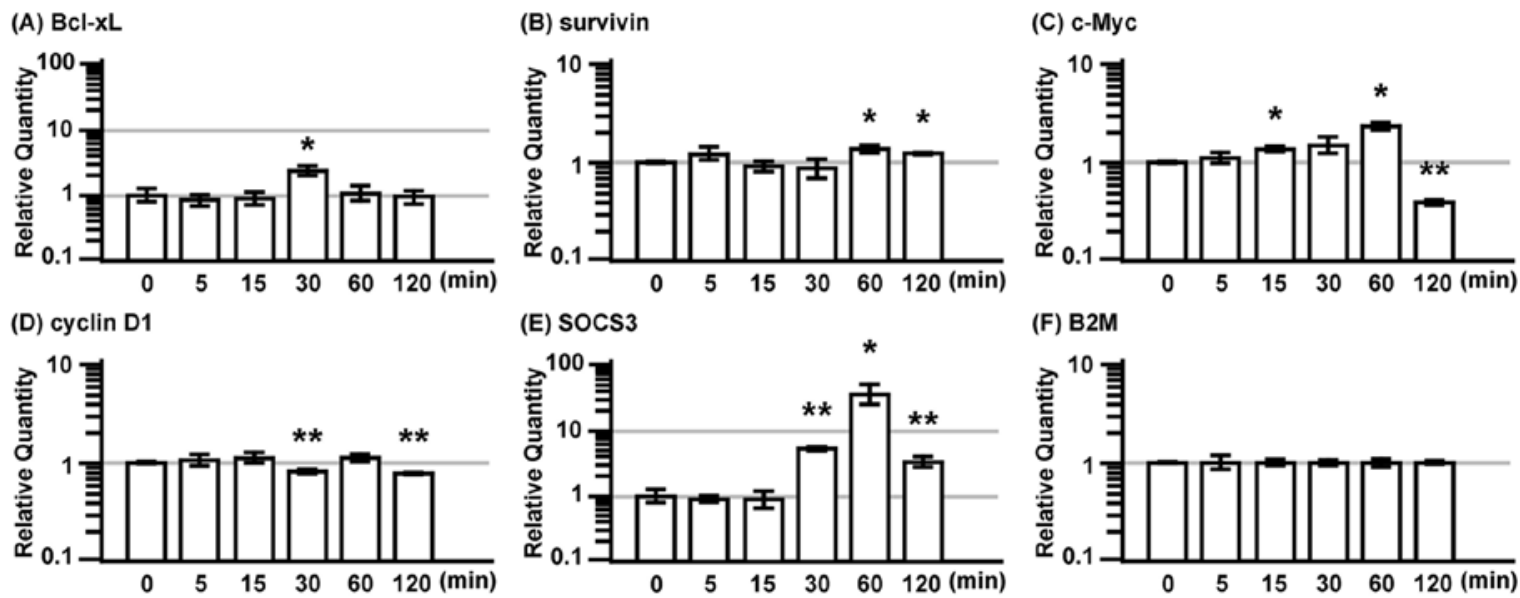

(F) B2M

(G) SOCS3 (HSC-4)

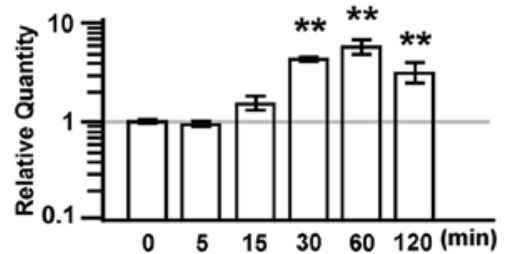

(H) SOCS3 (SAS)
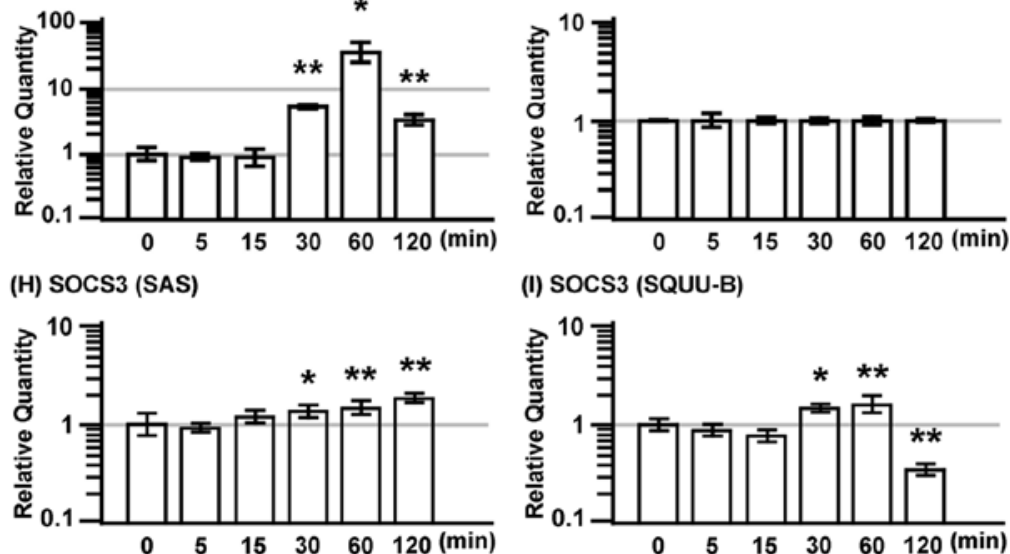

(I) SOCS3 (SQUU-B)

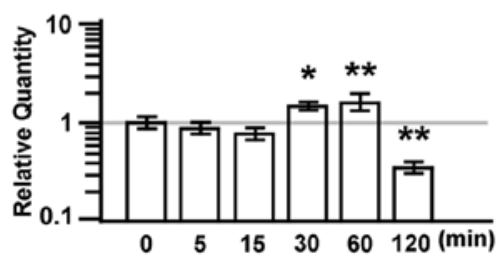

Figure 4. IL-22 transiently induces the expression of anti-apoptotic and mitogenic genes in MISK81-5 cells. MISK81-5 cells were treated with IL-22 (20 ng/ml) for various times as indicated. (A) Bcl-xL, (B) survivin, (C) c-Myc, (D) cyclin D1 and (E) SOCS3 were targeted as STAT3-downstream genes. Bcl-xL, c-Myc and SOCS3 exhibited a peak expression at 30,60 and $60 \mathrm{~min}$ after IL-22 stimulation, respectively. However, c-Myc gene expression was significantly decreased at $120 \mathrm{~min}$. IL-22 significantly increased the gene expression of survivin at 60 and $120 \mathrm{~min}$ and decreased cyclin D1 at 30 and $120 \mathrm{~min}$. (F) B2M was used as a reference gene. The SOCS gene expression in (G) HSC-4, (H) SAS and (I) SQUU-B cells treated with IL-22 (20 ng/ml) for various times is shown as indicated. Significant differences between the stimulated and unstimulated samples are indicated with single or double asterisks $\left({ }^{*} \mathrm{p}<0.05 ;{ }^{* *} \mathrm{p}<0.01\right)$
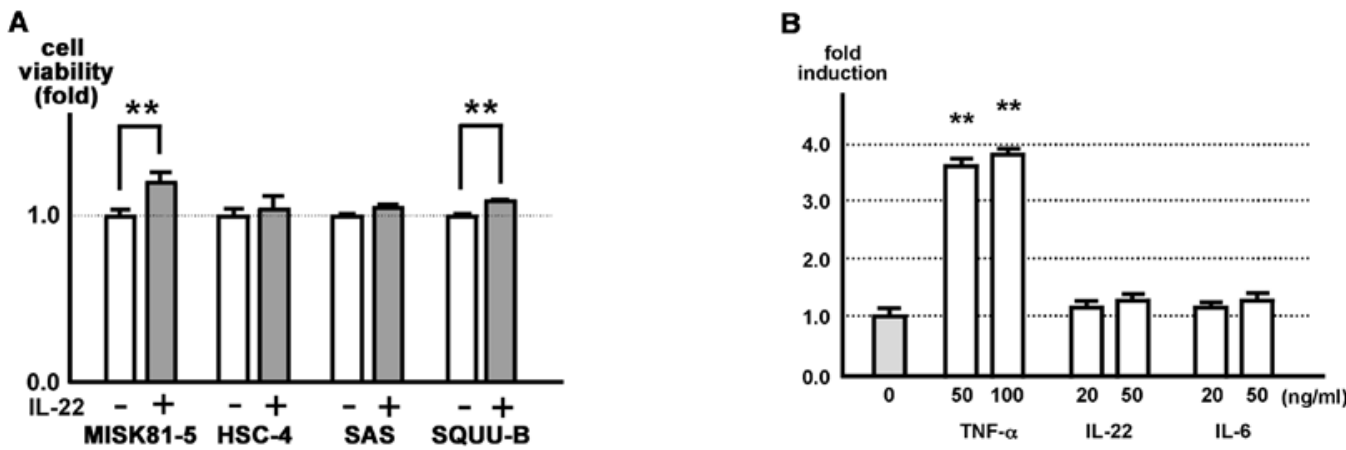

Figure 5. IL-22 affects MISK81-5 cell proliferation in vitro, but is negligibly associated with upregulation of the cellular NF-kB activation. (A) MISK81-5, HSC-4, SAS and SQUU-B cells were incubated with or without IL-22 $(20 \mathrm{ng} / \mathrm{ml})$ for $48 \mathrm{~h}$. The viability of MISK81-5 and SQUU-B cells treated with IL-22 was increased by 1.3- and 1.1-fold in comparison to the control cells, respectively. A significant difference was noted between the stimulated and control samples

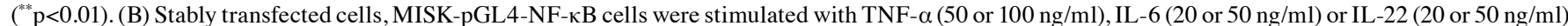
or with control medium. A luciferase assay was performed after $24 \mathrm{~h}$. Each ratio is indicated as the relative expression compared to the unstimulated control samples, and indicates the mean \pm SD (bars) of three values from one representative experiment. Significant differences in the transcriptional activity are indicated with double asterisks $(* * \mathrm{p}<0.01)$.

To examine whether IL-22 induces a reduction of the KRT1 expression through STAT3, we used siRNA to selectively reduce the STAT3 expression. STAT3 siRNA induced a significant downregulation of the STAT3 mRNA and protein levels (Fig. 7A and B), and inhibited the downregulation of KRT1 expression by IL-22 (Fig. 7C). Similarly, the transfection of the SAS cells with a siRNA for STAT partially inhibited the downregulation of the KRT1 expression by IL-22 (Fig. 7D). However, neither ERK nor pERK1/2 was affected by the STAT3 siRNA treatment (Fig. 7E).
IL-22 upregulates the expression of SERPINB3/4 (SCCA1/2) genes. Squamous cell carcinoma antigen (SCCA) 1 was originally identified in squamous cell carcinoma (SCC) of the uterine cervix (30). An elevated expression of SCCA1 and its isoform, SCCA2, has been used as a biomarker for aggressive SCC in the cervix, lung, head and neck (31-33). SCCA belongs to the serine protease inhibitor (Serpin) family of proteins, and SCCA1 and SCCA 2 are called SERPNB3 and SERPINB4, respectively. The SERPINB3 expression showed respective 1.2-, 2.4-. 1.7- and 2.0-fold increases in the MISK81-5, 
A

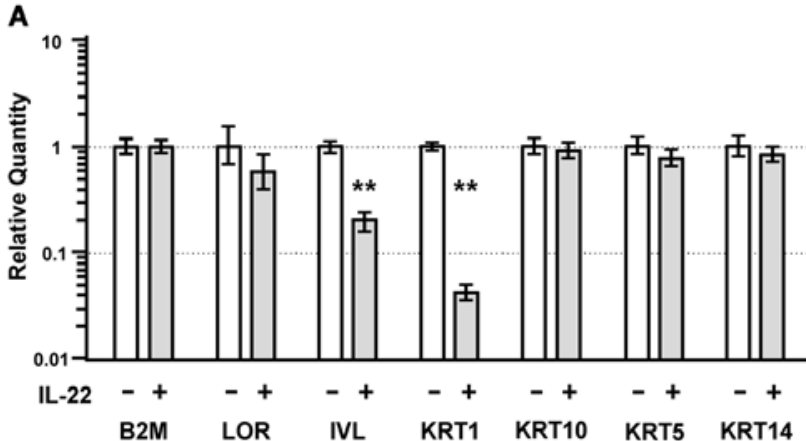

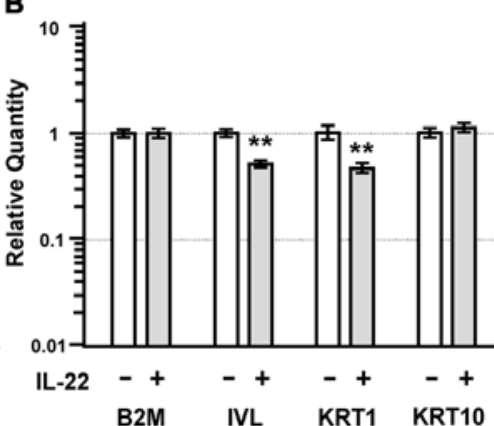

C

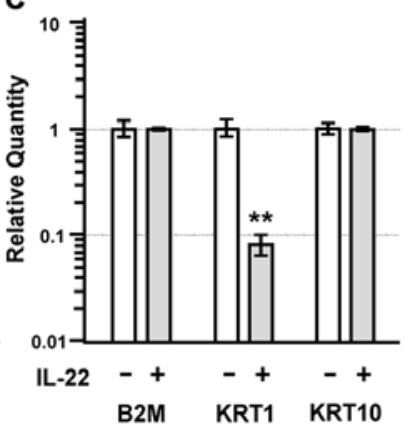

Figure 6. IL-22 treatment reduces the expression of keratinocyte differentiation-related genes. (A) The expression of loricrin (LOR), involucrin (IVL), keratin 1 (KRT1), keratin 10 (KRT10), keratin 5 (KRT5) and keratin 14 (KRT14) was compared between MISK81-5 cells stimulated with IL-22 for $24 \mathrm{~h}$ and unstimulated cells. (B) The expression of IVL, KRT1 and KRT10 was compared between HSC-4 cells stimulated with IL-22 for $24 \mathrm{~h}$ and unstimulated cells. (C) The expression of KRT1 was significantly decreased in the IL-22-treated SAS cells compared to that in unstimulated cells. Significant differences in the gene expression are indicated by double asterisks $\left({ }^{* *} \mathrm{p}<0.01\right)$.
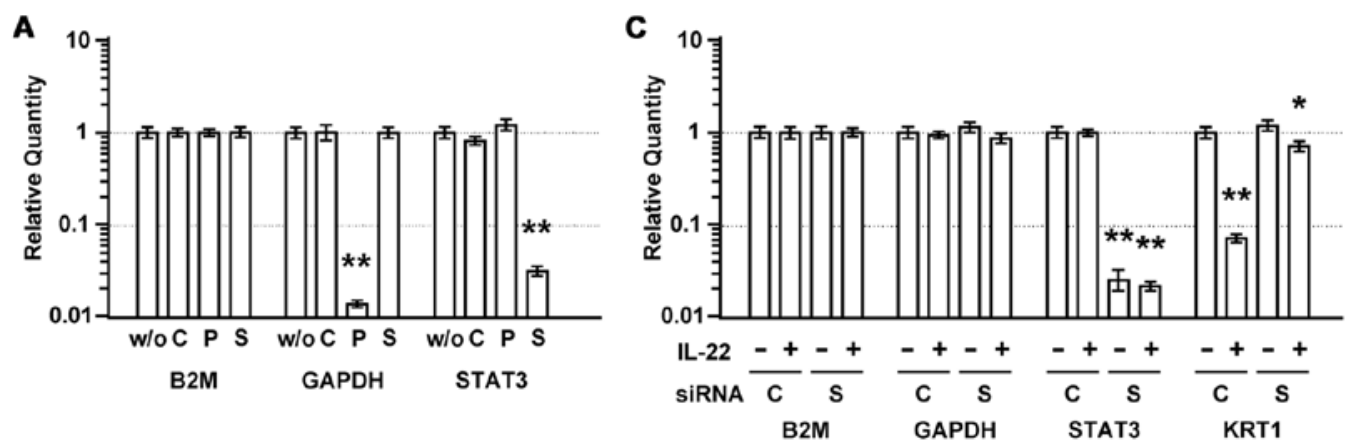

B

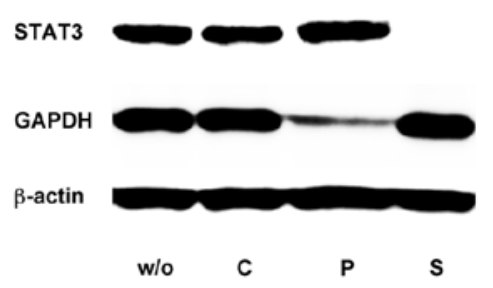

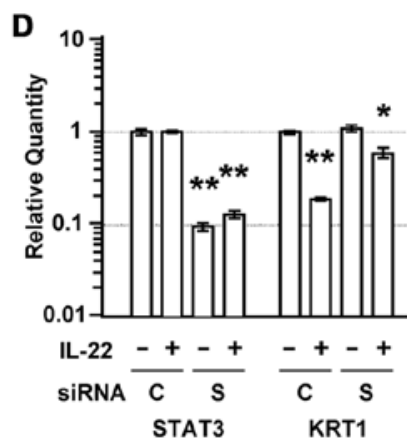

$\mathbf{E}$

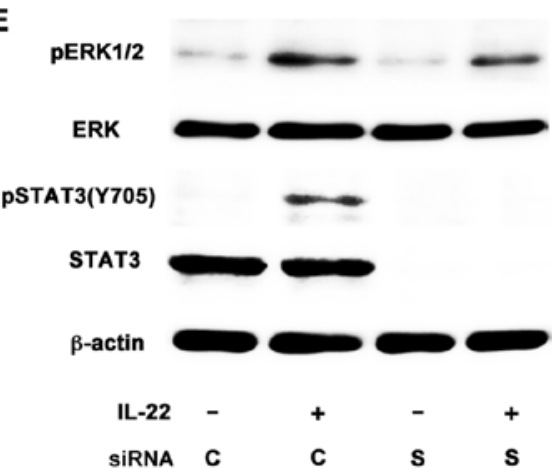

Figure 7. STAT3 siRNA inhibits IL-22-induced reduction of KRT1 expression, but it has little impact on pERK. (A) siRNA selectively reduced the gene expression in the MISK81-5 cells at $30 \mathrm{~h}$ after siRNA transfection. Significant differences in the gene expression are indicated by double asterisks ("$\left.{ }^{* *}<0.01\right)$. B2M was used as a reference gene. (B) An immunoblot analysis also revealed that GAPDH and STAT3 siRNAs cause a depletion of the GAPDH and STAT3 protein levels in the MISK81-5 cells, respectively. (C) At $30 \mathrm{~h}$ before IL-22 stimulation, the MISK81-5 cells were transfected with siRNA. The expression of B2M, GAPDH, STAT3 and KRT1 was compared between MISK81-5 cells after IL-22 stimulation for $24 \mathrm{~h}$ and unstimulated cells ( $\left.{ }^{*} \mathrm{p}<0.05 ;{ }^{* *} \mathrm{p}<0.01\right)$. (D) The downregulation of KRT1 expression by IL-22 was inhibited in the SAS cells transfected with a siRNA for STAT3 and in unstimulated cells. Significant differences in the gene expression are indicated by single or double asterisks ( $\left.{ }^{*} \mathrm{p}<0.05 ;{ }^{* *} \mathrm{p}<0.01\right)$. (E) At $30 \mathrm{~h}$ after siRNA transfection, the MISK81-5 cells were treated with IL-22 for $10 \mathrm{~min}$. Total cell lysates (10 $\mu \mathrm{g} / \mathrm{sample})$ were analyzed by immunoblotting with an antibody against pY705-STAT3. The membrane was repeatedly reprobed and immunoblotted with an anti-pERK1/2, anti-total STAT3, or an anti-ERK antibody and then with an anti- $\beta$-actin antibody. w/o, sample without siRNA treatment; C, sample treated with negative control siRNA; P, sample treated with GAPDH siRNA as a positive control; S, sample treated with STAT3 siRNA.

HSC-4, SAS and SQUU-B cells treated with IL-22 $(50 \mathrm{ng} / \mathrm{ml})$ compared with control samples. The SERPINB4 expression also showed 1.8-, 3.6-. 1.6- and 3.0-fold increases, respectively, in the MISK81-5, HSC-4, SAS and SQUU-B cells treated with IL-22 $(50 \mathrm{ng} / \mathrm{ml})$ compared with control samples. A significant difference in the expression levels of these genes was noted between all of the IL-22-treated $(50 \mathrm{ng} / \mathrm{ml})$ cells and control cells, except for the SERPINB3 expression in MISK81-5 cells $(\mathrm{p}<0.01$ or $\mathrm{p}<0.05)$ (Fig. 8A and B).

\section{Discussion}

Immunostaining for IL-22R revealed that the intensity was increased in the primary and metastatic OSCC cells. IL-22 

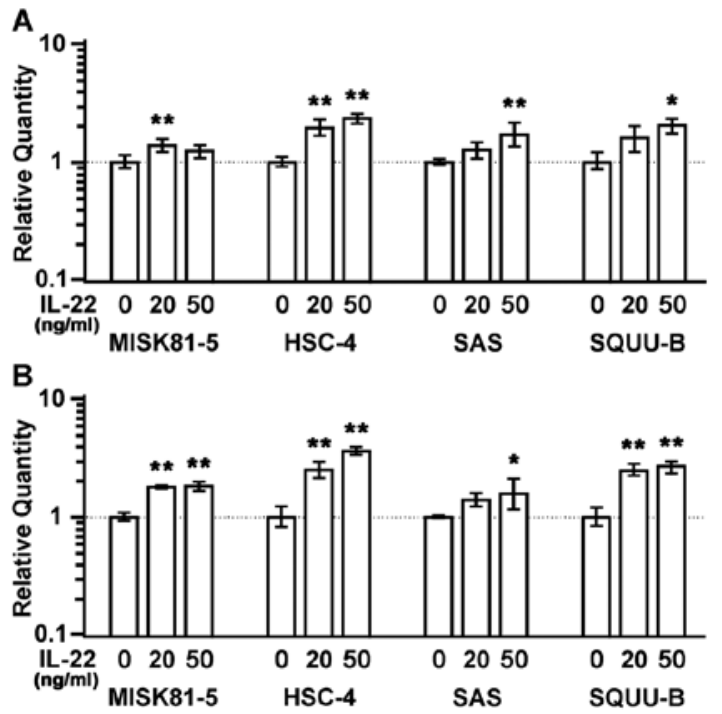

Figure 8. IL-22 treatment induces the upregulated expression of SERPINB3/4 genes in OSCC cells. The expression of the (A) SERPINB3 and (B) SERPINB4 genes was increased in the MISK81-5, HSC-4, SAS and SQUU-B cells stimulated with IL-22 (20 or $50 \mathrm{ng} / \mathrm{ml})$ compared with those cultured in the control medium. Significant differences in the gene expression are indicated by single or double asterisks $\left({ }^{*} \mathrm{p}<0.05 ;{ }^{* *} \mathrm{p}<0.01\right)$.

induced the transient phosphorylation of STAT3 and led to its translocation into the nucleus. IL-22 activated the ERK and p38 MAPK pathways, but did not have a significant effect on NF- $\kappa$ B. IL-22 mildly affected the proliferation of OSCC cells and downregulated the expression of keratinocyte differentiation-related genes. STAT3 siRNA inhibited the IL-22-mediated downregulation of the keratinocyte differentiation-related genes, but did not affect the activation of the ERK pathway. The expression of the SERPINB3/4 genes in OSCC cells was upregulated by IL-22 stimulation, thus suggesting that IL-22 plays a key role in the biology of OSCC cells.

Immunohistochemical staining showed that IL-22R was expressed in OSCC. The expression of both IL-22 receptor chains was confirmed in MISK81-5, HSC-3, HSC-4, SAS and SQUU-B OSCC cell lines by RT-PCR. In the immunoblotting analysis, MISK81-5 cells showed the transient phosphorylation of STAT3 at Y705 by IL-22 stimulation. Similar results were reported for IL-22 stimulation in other types of cells $(13,23)$. In the immunocytochemistry experiments, a transient translocation of STAT3 into the nucleus was observed in MISK81-5 cells. When pY705-STAT3 decreased, STAT3 was again detected in the cytoplasm, similar to unstimulated cells. These results suggest that pY705 mediated the translocation of pSTAT3. This finding was supported by the study of Zhong et al (34), in which the phosphorylation of STAT3 at Y705 was shown to lead to the translocation of STAT3 into the nucleus, thereby activating the transcription of multiple target genes. Conversely, the change in pS727-STAT3 was subtle in this study. The phosphorylation of STAT3 at S727 in OSCC cells was different from that in the study of Lejeune et al (13) who showed transient increases in pS727-STAT3 in hepatoma cells after treatment with IL-22. Although pS727 is thought to play a regulatory role in STAT3 activation, resulting in its maximal transcriptional activity (35), the function of pS727 remains unclear in this study. In addition, STAT3 phosphorylation was not observed in HSC-3 cells following IL-22 stimulation. This result indicates that the IL-22 receptors were functional in MISK81-5 cells, but that not all squamous cell carcinomas activate STAT3 signaling after exposure to IL-22.

The activity of MAP kinases such as ERK and p38 after IL-22 stimulation in this study (Fig. 2), is partly reminiscent of that in hepatoma cells observed in other studies $(13,14)$. After IL-22 stimulation, ERK activation preceded that of STAT3. The phosphorylation of ERK1/2 induced by IL-22 stimulation was not affected by STAT3 siRNA (Fig. 7). These results suggest that other STAT3-independent mechanisms are acting on MISK81-5 cells under IL-22 stimulation. While IL-22 transiently activated ERK1/2 and induced a delayed phosphorylation of p38 MAP kinase, ERK1/2 phosphorylation decreased to less than the control level after $30 \mathrm{~min}$. A similar result was seen in the IL-22 treatment of murine breast adenocarcinoma EMT6, in which ERK1/2 phosphorylation was inhibited by IL-22, thus leading to cell cycle arrest (17). Additionally, the transient activation of STAT3 also involved the transient upregulation of SOCS3 expression in OSCC cells. The transient upregulation of SOCS3 expression may affect the transient activation of STAT3 and STAT3-associated factors in OSCC cells, as SOCS3 acts as a suppressor of STAT signaling, while SOCS3 is one of the downstream genes of STAT3. IL-22 may constitutively contribute to the activation of STAT3 and the expression of anti-apoptotic and mitogenic genes in OSCC cells under the suppression of SOCS3, since SOCS3 causes growth inhibition in SCC cell lines $(25,36)$. Indeed, IL-22 mildly stimulated the cell proliferation of MISK81-5 and SQUU-B cells in this study. The proliferation of HSC-4 and SAS cells was limited after IL-22 stimulation. This stimulation may be due to a complicated synergistic effect among the transiently increased activity of ERK $1 / 2$ and the expression of c-Myc and cyclin D1 genes, the inhibition of ERK1/2 phosphorylation, and/or SOCS3 expression.

Keratinocytes are thought to show changes in their expression and synthesis of cytoskeletal proteins after exposure to proliferative or inflammatory cytokines (37). IVL, LOR, KRT1 and KRT10 are the characteristic markers of normal suprabasal keratinocytes (38). IL-22 significantly reduced the expression of the IVL and/or KRT1 genes in MISK81-5, HSC-4 and SAS cells. Our results indicated that IL-22 could thus play a role in regulating the terminal differentiation of OSCC cells through STAT3 activation similar to the effects in keratinocytes. Since these factors play important roles during the terminal differentiation of keratinocytes and are associated with apoptotic processes (39-42), the control of the IL-22 function in OSCCs may therefore make it possible to induce apoptosis in OSCC cells via differentiation.

In this study, IL-22 induced the upregulation of SERPINB3 and SERPINB4 expression in OSCC cells. The downregulation of SERPINB3 by an antisense method significantly increased the cellular susceptibility to drug-induced apoptosis (43). Our previous study showed that SERPINB3/B4 contributed, at least in part, to preventing TNF- $\alpha$ induced cell death by impeding the cytochrome $c$ release from the mitochondria (44). Ahmed et al (45) demonstrated that squamous carcinoma cells promote cell survival through activation of SERPINB3/ B4 genes by activated STAT3. Thus, IL-22 may play a role in 
the attenuation of drug-induced apoptosis by the increasing the expression of SERPINB3/B4 in cancer cells.

Our present study shows that IL-22 affects several important functions of OSCC cells via the STAT3-dependent and/ or -independent pathways, suggesting that IL-22 may play a role in carcinoma cell differentiation and the upregulation of SERPINB3/B4, well-known biomarkers for SCC. However, the response against IL-22 varies in OSCC cell lines. Further studies are required to elucidate the mechanisms by which IL-22 is involved in the biology of OSCC carcinogenesis. Elucidating the functions of IL-22 could lead to the development of new perspectives on this disease, and potentially new therapies with few side-effects, thereby improving the treatment of patients with OSCC.

\section{Acknowledgements}

The present study was funded in part by Grant-in-Aid from the Ministry of Education, Culture, Sports, Science and Technology of Japan, \#20390466, \#23659880 (to H.S.) and \#80117077 (to S.O.).

\section{References}

1. Chidzonga MM and Mahomva L: Squamous cell carcinoma of the oral cavity, maxillary antrum and lip in a Zimbabwean population: a descriptive epidemiological study. Oral Oncol 42: 184-189, 2006

2. Chidzonga MM: Oral malignant neoplasia: a survey of 428 cases in two Zimbabwean hospitals. Oral Oncol 42: 177-183, 2006.

3. Dimery IW and Hong WK: Overview of combined modality therapies for head and neck cancer. J Natl Cancer Inst 85: 95-111, 1993.

4. Schantz SP and Yu GP: Head and neck cancer incidence trends in young Americans, 1973-1997, with a special analysis for tongue cancer. Arch Otolaryngol Head Neck Surg 128: 268-274, 2002.

5. Llewellyn CD, Linklater K, Bell J, Johnson NW and Warnakulasuriya KA: Squamous cell carcinoma of the oral cavity in patients aged 45 years and under: a descriptive analysis of 116 cases diagnosed in the South East of England from 1990 to 1997. Oral Oncol 39: 106-114, 2003.

6. Dudley ME, Wunderlich JR, Robbins PF, Yang JC, Hwu P, Schwartzentruber DJ, Topalian SL, Sherry R, Restifo NP, Hubicki AM, et al: Cancer regression and autoimmunity in patients after clonal repopulation with antitumor lymphocytes. Science 298: 850-854, 2002.

7. Négrier S, Escudier B, Gomez F, Douillard JY, Ravaud A, Chevreau C, Buclon M, Pérol D and Lasset C: Prognostic factors of survival and rapid progression in 782 patients with metastatic renal carcinomas treated by cytokines: a report from the Groupe Français d'Immunothérapie. Ann Oncol 13: 1460-1468, 2002.

8. Rosenberg SA: Progress in human tumour immunology and immunotherapy. Nature 411: 380-384, 2001.

9. Boniface K, Guignouard E, Pedretti N, Garcia M, Delwail A, Bernard FX, Nau F, Guillet G, Dagregorio G, Yssel H, et al: A role for T cell-derived interleukin 22 in psoriatic skin inflammation. Clin Exp Immunol 150: 407-415, 2007.

10. Wolk K and Sabat R: Interleukin-22: a novel T- and NK-cell derived cytokine that regulates the biology of tissue cells Cytokine Growth Factor Rev 17: 367-380, 2006.

11. Trifari S, Kaplan CD, Tran EH, Crellin NK and Spits H: Identification of a human helper $\mathrm{T}$ cell population that has abundant production of interleukin 22 and is distinct from $\mathrm{T}(\mathrm{H})-17, \mathrm{~T}(\mathrm{H}) 1$ and $\mathrm{T}(\mathrm{H}) 2$ cells. Nat Immunol 10: 864-871, 2009

12. Wolk K, Kunz S, Witte E, Friedrich M, Asadullah K and Sabat R: IL-22 increases the innate immunity of tissues. Immunity 21 : 241-254, 2004.

13. Lejeune D, Dumoutier L, Constantinescu S, Kruijer W, Schuringa JJ and Renauld JC: Interleukin-22 (IL-22) activates the JAK/STAT, ERK, JNK, and p38 MAP kinase pathways in a rat hepatoma cell line. Pathways that are shared with and distinct from IL-10. J Biol Chem 277: 33676-33682, 2002.
14. Radaeva S, Sun R, Pan HN, Hong F and Gao B: Interleukin 22 (IL-22) plays a protective role in T cell-mediated murine hepatitis: IL-22 is a survival factor for hepatocytes via STAT3 activation. Hepatology 39: 1332-1342, 2004.

15. Ziesché E, Bachmann M, Kleinert H, Pfeilschifter J and Mühl H: The interleukin-22/STAT3 pathway potentiates expression of inducible nitric-oxide synthase in human colon carcinoma cells. J Biol Chem 282: 16006-16015, 2007.

16. Zhang W, Chen Y, Wei H, Zheng C, Sun R, Zhang J and Tian Z: Antiapoptotic activity of autocrine interleukin-22 and therapeutic effects of interleukin-22-small interfering RNA on human lung cancer xenografts. Clin Cancer Res 14: 6432-6439, 2008.

17. Weber GF, Gaertner FC, Erl W, Janssen KP, Blechert B, Holzmann B, Weighardt $\mathrm{H}$ and Essler M: IL-22-mediated tumor growth reduction correlates with inhibition of ERK1/2 and AKT phosphorylation and induction of cell cycle arrest in the G2-M phase. J Immunol 177: 8266-8272, 2006.

18. Nagakawa $\mathrm{H}$, Shimozato $\mathrm{O}$, Yu L, Takiguchi Y, Tatsumi K, Kuriyama $\mathrm{T}$ and Tagawa M: Expression of interleukin-22 in murine carcinoma cells did not influence tumour growth in vivo but did improve survival of the inoculated hosts. Scand J Immunol 60: 449-454, 2004

19. Matsuo K, Ishibashi Y, Kobayashi I, Ozeki S, Ohishi M, Tange T, Hirata J, Kiyoshima T and Sakai H: New human oral squamous carcinoma cell line and its tumorigenic subline producing granulocyte colony-stimulating factor. Jpn J Cancer Res 85: 1257-1262, 1994.

20. Takahashi K, Kanazawa H, Akiyama Y, Tasaki S, Takahara M, Muto T, Tanzawa $\mathrm{H}$ and Sato K: Establishment and characterization of a cell line (SAS) from poorly differentiated human squamous cell carcinoma of the tongue. J Jpn Stomatol Soc 38: 20-28, 1989.

21. Morifuji M, Taniguchi S, Sakai H, Nakabeppu Y and Ohishi M: Differential expression of cytokeratin after orthotopic implantation of newly established human tongue cancer cell lines of defined metastatic ability. Am J Pathol 156: 1317-1326, 2000.

22. Yuan JS, Reed A, Chen F and Stewart CN Jr: Statistical analysis of real-time PCR data. BMC Bioinformatics 7: 85, 2006.

23. Wolk K, Witte E, Wallace E, Docke WD, Kunz S, Asadullah K, Volk HD, Sterry W and Sabat R: IL-22 regulates the expression of genes responsible for antimicrobial defense, cellular differentiation, and mobility in keratinocytes: a potential role in psoriasis. Eur J Immunol 36: 1309-1323, 2006.

24. Boniface K, Bernard FX, Garcia M, Gurney AL, Lecron JC and Morel F: IL-22 inhibits epidermal differentiation and induces proinflammatory gene expression and migration of human keratinocytes. J Immunol 174: 3695-3702, 2005.

25. Lee TL, Yeh J, Van Waes C and Chen Z: Epigenetic modification of SOCS-1 differentially regulates STAT3 activation in response to interleukin-6 receptor and epidermal growth factor receptor signaling through JAK and/or MEK in head and neck squamous cell carcinomas. Mol Cancer Ther 5: 8-19, 2006.

26. Wei LH, Kuo ML, Chen CA, Chou CH, Cheng WF, Chang MC, Su JL and Hsieh CY: The anti-apoptotic role of interleukin-6 in human cervical cancer is mediated by up-regulation of Mcl-1 through a PI3-K/Akt pathway. Oncogene 20: 5799-5809, 2001.

27. Zhong $\mathrm{H}$ and Simons JW: Direct comparison of GAPDH, beta-actin, cyclophilin, and 28S rRNA as internal standards for quantifying RNA levels under hypoxia. Biochem Biophys Res Commun 259: 523-526, 1999.

28. Hagihara K, Nishikawa T, Isobe T, Song J, Sugamata Y and Yoshizaki K: IL-6 plays a critical role in the synergistic induction of human serum amyloid A (SAA) gene when stimulated with proinflammatory cytokines as analyzed with an SAA isoform real-time quantitative RT-PCR assay system. Biochem Biophys Res Commun 314: 363-369, 2004.

29. Vandesompele J, De Preter K, Pattyn F, Poppe B, Van Roy N, De Paepe A and Speleman F: Accurate normalization of real-time quantitative RT-PCR data by geometric averaging of multiple internal control genes. Genome Biol 3: 0034, 2002.

30. Kato $\mathrm{H}$ and Torigoe $\mathrm{T}$ : Radioimmunoassay for tumor antigen of human cervical squamous cell carcinoma. Cancer 40: 1621-1628, 1977.

31. Duk JM, de Bruijn HW, Groenier KH, Hollema H, ten Hoor KA, et al: Cancer of the uterine cervix: sensitivity and specificity of serum squamous cell carcinoma antigen determinations. Gynecol Oncol 39: 186-194, 1990. 
32. Duk JM, Groenier KH, de Bruijn HW, Hollema H, ten Hoor KA, van der Zee AG and Aalders JG: Pretreatment serum squamous cell carcinoma antigen: a newly identified prognostic factor in early-stage cervical carcinoma. J Clin Oncol 14: 111-118, 1996.

33. Molina R, Filella X, Augé JM, Fuentes R, Bover I, Rifa J, Moreno V, Canals E, Viñolas N, Marquez A, et al: Tumor markers (CEA, CA 125, CYFRA 21-1, SCC and NSE) in patients with non-small cell lung cancer as an aid in histological diagnosis and prognosis. Comparison with the main clinical and pathological prognostic factors. Tumour Biol 24: 209-218, 2003.

34. Zhong Z, Wen Z and Darnell JE Jr: Stat3: a STAT family member activated by tyrosine phosphorylation in response to epidermal growth factor and interleukin-6. Science 264: 95-98, 1994.

35. Schuringa JJ, Schepers H, Vellenga E and Kruijer W: Ser727dependent transcriptional activation by association of $\mathrm{p} 300$ with STAT3 upon IL-6 stimulation. FEBS Lett 495: 71-76, 2001.

36. Weber A, Hengge UR, Bardenheuer W, Tischoff I, Sommerer F, Mark warth A, Dietz A, Wittekind C and Tannapfel A: SOCS-3 is frequently methylated in head and neck squamous cell carcinoma and its precursor lesions and causes growth inhibition. Oncogene 24: 6699-6708, 2005.

37. Hernández-Quintero M, Kuri-Harcuch W, González Robles A and Castro-Muñozledo F: Interleukin- 6 promotes human epidermal keratinocyte proliferation and keratin cytoskeleton reorganization in culture. Cell Tissue Res 325: 77-90, 2006.

38. Eichner R, Bonitz P and Sun TT: Classification of epidermal keratins according to their immunoreactivity, isoelectric point, and mode of expression. J Cell Biol 98: 1388-1396, 1984.
39. Fuchs E: Epidermal differentiation: the bare essentials. J Cell Biol 111: 2807-2814, 1990.

40. Porter RM, Leitgeb S, Melton DW, Swensson O, Eady RA and Magin TM: Gene targeting at the mouse cytokeratin 10 locus: severe skin fragility and changes of cytokeratin expression in the epidermis. J Cell Biol 132: 925-936, 1996.

41. Fuchs E and Weber K: Intermediate filaments: structure, dynamics, function, and disease. Annu Rev Biochem 63: 345-382, 1994.

42. Fuchs E: Keratins and the skin. Annu Rev Cell Dev Biol 11: 123-153, 1995.

43. Suminami Y, Nagashima S, Murakami A, Nawata S, Gondo T, Hirakawa H, Numa F, Silverman GA and Kato H: Suppression of a squamous cell carcinoma (SCC)-related serpin, SCC antigen, inhibits tumor growth with increased intratumor infiltration of natural killer cells. Cancer Res 61: 1776-1780, 2001.

44. Hashimoto K, Kiyoshima T, Matsuo K, Ozeki S and Sakai H: Effect of SCCA1 and SCCA2 on the suppression of TNF-alphainduced cell death by impeding the release of mitochondrial cytochrome $\mathrm{c}$ in an oral squamous cell carcinoma cell line. Tumour Biol 26: 165-172, 2005.

45. Ahmed ST and Darnell JE Jr: Serpin B3/B4, activated by STAT3, promote survival of squamous carcinoma cells. Biochem Biophys Res Commun 378: 821-825, 2009. 